\title{
Prospective study on food fortification with vitamin D among adolescent females in Finland: minor effects
}

\author{
Marjo Lehtonen-Veromaa ${ }^{1,2}$, Timo Möttönen ${ }^{1,3}$, Aila Leino ${ }^{4,5}$, Olli J. Heinonen ${ }^{1,2}$, Essi Rautava ${ }^{1,2}$ \\ and Jorma Viikari ${ }^{1,3}$ \\ ${ }^{1}$ University of Turku, Kiinamyllynkatu 13, Turku FIN 20520, Finland \\ ${ }^{2}$ Sports \& Exercise Medicine Unit, Department of Physiology, Paavo Nurmi Centre, University of Turku, Kiinamyllynkatu 10, \\ Turku FIN 20520, Finland \\ ${ }^{3}$ Department of Medicine, Turku University Central Hospital, Kiinamyllynkatu 4-8, Turku FIN 20520, Finland \\ ${ }^{4}$ TYKSLAB, Hospital District of Southwest Finland, Turku University Central Hospital, Kiinamyllynkatu 4-8, Turku FIN 20520, \\ Finland \\ ${ }^{5}$ Department of Clinical Chemistry, University of Turku, Kiinamyllynkatu 4-8, Turku FIN 20520, Finland \\ (Received 16 May 2007 - Revised 26 November 2007 - Accepted 28 November 2007 - First published online 14 February 2008)
}

\begin{abstract}
Vitamin D insufficiency is common particularly during wintertime. After the recommendation by the Ministry of Social Affairs and Health, Finnish fluid milks and margarines have been fortified with vitamin D since February 2003. The aims of the present study were to examine the impact of vitamin D fortification of food supplies on serum 25-hydroxyvitamin D $(\mathrm{S}-25(\mathrm{OH}) \mathrm{D})$ concentrations and on daily dietary vitamin D intake among adolescent females. One hundred and forty-two girls of Caucasian ethnicity aged 12-18 years completed semi-quantitative FFQ from which the dietary vitamin D and Ca intakes were calculated. S-25(OH)D was measured by radioimmunoassay. The study was performed from February-March 2000 to February-March 2004, one year after the initiation of fortification. The mean dietary intake of vitamin D was $<7.5 \mu \mathrm{g}$ in $91.5 \%$ of the adolescent girls in 2000 and $83.8 \%$ in 2004. The midwinter mean S-25(OH)D concentration did not change significantly during the follow-up period $(48.3$ v. $48.1 \mathrm{nmol} / \mathrm{l}, \mathrm{NS})$. The proportion of participants who had S-25(OH)D concentration $<50 \mathrm{nmol} / 1$ was $60.6 \%$ in 2000 and $65.5 \%$ in 2004. Only $7.0 \%$ of the participants had an adequate S-25(OH)D ( $\geq 75 \mathrm{nmol} / 1)$ level in 2000 or 4 years later. The vitamin D fortification of fluid milks and margarines was inadequate to prevent vitamin D insufficiency. There are numerous adolescent girls and women who are not reached by the current fortification policy. Therefore new innovative and feasible ways of improving vitamin $\mathrm{D}$ nutrition are urged.
\end{abstract}

Adolescence: Fortification: Serum 25-hydroxyvitamin D: Insufficiency

The adequacy of vitamin D intake by children and adolescents has been the subject of much research ${ }^{(1-4)}$. According to studies on serum 25-hydroxyvitamin D (S-25(OH)D) concentrations, a valid clinical marker of vitamin $\mathrm{D}$ stores ${ }^{(5)}$, the prevalence of insufficient vitamin $\mathrm{D}$ is high in the population during winter compared to summer ${ }^{(2,6)}$.

Optimal intestinal $\mathrm{Ca}$ absorption occurs at a S-25(OH)D concentration of approximately $80 \mathrm{nmol} / \mathrm{l}$, and hyperparathyroidaemia in the elderly is minimized at the same $25(\mathrm{OH}) \mathrm{D}$ concentration. Osteoporotic fractures are reduced when $\mathrm{S}-25(\mathrm{OH}) \mathrm{D}$ is about $80 \mathrm{nmol} / \mathrm{l}^{(7)}$. There is an inverse relationship between the S-25(OH)D and parathyroid hormone (PTH) concentrations also in adolescents ${ }^{(8,9)}$. Recent studies confirm that vitamin D is important also for musculoskeletal health, particularly in girls during a critical period of growth ${ }^{(4,9-11)}$. Recent findings demonstrate also an association between low vitamin $\mathrm{D}$ concentrations and severe diseases, not excluding cancers $^{(12,13)}$.
National policies on food fortification or individual supplementation with vitamin $\mathrm{D}$ have been introduced by the European Union and also by many individual European countries. The Optiford project was established by a coalition of scientists to optimize vitamin D fortification in the northern European Countries ${ }^{(14)}$. Corrective strategies have also been proposed to allow children and adolescents living in northern countries to maintain healthy circulating $25(\mathrm{OH}) \mathrm{D}$ concentrations throughout the year despite inadequate exposure to sun light ${ }^{(3,4,14,15)}$.

Since February 2003, following the recommendation by the Finnish Ministry of Social Affairs and Health, fluid milks $(0.5 \mu \mathrm{g} / 100 \mathrm{ml})$, margarines and spreads $(10 \mu \mathrm{g} / 100 \mathrm{~g})$ have been fortified by vitamin $\mathrm{D}$ in Finland. According to a recent report fortification has indeed improved, in general, the mean vitamin D intake and status in Finland ${ }^{(16)}$. Nevertheless, the mean dietary intake of vitamin $\mathrm{D}$ by children and 14- to 17-year-old girls was not in accordance with the current

Abbreviations: MET, ratio of work metabolic rate hours; PTH, parathyroid hormone; 25(OH)D, hydroxyvitamin D; S-25(OH)D, serum 25(OH)D; S-PTH, serum PTH. * Corresponding author: Dr Marjo Lehtonen-Veromaa, fax +358 2 2502610, email marjo.lehtonen-veromaa@pulssi.fi 
recommendations. Also, the mean $\mathrm{S}-25(\mathrm{OH}) \mathrm{D}$ was still low $(<50 \mathrm{nmol} / \mathrm{l})$ among 14 - to 17 -year-old girls, young adults, and middle-aged women ${ }^{(16)}$.

The aim of this study was to examine the impact of vitamin $\mathrm{D}$ fortification of liquid milk products, margarines and spreads on $\mathrm{S}-25(\mathrm{OH}) \mathrm{D}$ concentrations and on the daily dietary vitamin $\mathrm{D}$ intake among adolescent females before and one year after fortification had been initiated.

\section{Subjects, materials and methods}

\section{Subjects}

The study population comprised 171 healthy Caucasian girls aged 12-18 years at baseline in 2000 (sixty-two competing gymnasts, fifty-eight competing runners and fifty-one non-athletic controls); 142 (fifty-two gymnasts, forty-six runners and forty-four controls) of these girls were re-evaluated in 2004. The non-attending persons were either living too far away or could not find enough time to attend for follow-up. The baseline values of the dropouts did not differ from those of the participants (data not shown). The participants were recruited from local sports clubs and schools in the city of Turku and its vicinity. None of the participants was known to have any chronic disease or disorders affecting bone metabolism.

The study protocol was approved by the Ethics Review Committee of the Hospital District of Southwestern Finland and carried out in accordance with the Declaration of Helsinki. Written informed consent was obtained from each participant and from her parent or guardian when the girl was younger than 18 years.

The study period was February-March in both 2000 and 2004. Height was measured with a fixed stadiometer (Harpenden Stadiometer, Holtain, Crymych, UK) to the nearest $0.1 \mathrm{~cm}$ and the weight of the subjects in light clothing recorded with an electronic scale (EKS exclusive, EKS International, Sweden) to the nearest $0 \cdot 1 \mathrm{~kg}$. The BMI was calculated as $\mathrm{kg} / \mathrm{m}^{2}$.

Pubertal stage. The stage of pubertal development was individually evaluated ${ }^{(17)}$. Based on pubertal development, the participants were classified into three groups: pre-pubertal (Tanner stage 1), pubertal (Tanner stages 2-4), and mature (Tanner stage 5).

Assessment of nutrient intake. The intakes of vitamin D and $\mathrm{Ca}$ were estimated by a self-reported questionnaire, as described by Lehtonen-Veromaa et al. ${ }^{(2)}$. Another validated questionnaire involving $\mathrm{Ca}$ intake was filled in at the end of study ${ }^{(18)}$. The questionnaire was revised and up-dated on vitamin D intake because vitamin D fortification in food products changed in Finland in February 2003 after the recommendation by the Ministry of Social Affairs and Health. Margarines and spreads $(10 \mu \mathrm{g} / 100 \mathrm{~g})$, milk and sour milk $(0.5 \mu \mathrm{g} /$ $100 \mathrm{ml})$, and lactose-free special diet drinks $(0.5 \mu \mathrm{g} / 100 \mathrm{ml})$ are currently fortified in Finland. Earlier, vitamin D fortification was allowed in margarines $(7 \mu \mathrm{g} / 100 \mathrm{~g})$, and fat-free and $1 \%$ fat milk $(0.08 \mu \mathrm{g} / 100 \mathrm{ml})$. The questionnaire on the frequency of vitamin $\mathrm{D}$ and $\mathrm{Ca}$ supplementation was filled in.

Assessment of physical activity. The subjects completed a detailed questionnaire on their physical activity in 2000 and again in 2004 as described by Rautava et al. ${ }^{(19)}$. On the basis of this information, leisure time physical activity was calculated the ratio of work metabolic rate hours (MET) per week.

\section{Laboratory studies}

Antecubital blood samples were taken at study visits between 08.00 and 09.00 hours after an overnight fast. Serum was separated and stored at $-70^{\circ} \mathrm{C}$. All samples from an individual subject were assayed together in the same run at the end of the study. Serum samples for $25(\mathrm{OH}) \mathrm{D}$ were protected from light during processing and measured by radioimmunoassay (DiaSorin Corporation, Stillwater, Minnesota, USA). The intra-assay $\mathrm{CV}$ was $2.0 \%$ and the inter-assay $\mathrm{CV} 9.7 \%$ at a level of $33.5 \mathrm{nmol} / \mathrm{l}$ ( $n$ 25). Vitamin $\mathrm{D}$ insufficiency was defined as $\mathrm{S}-25(\mathrm{OH}) \mathrm{D}$ concentration $<50 \mathrm{nmol} / \mathrm{l}^{(20)}$. Serum PTH (S-PTH) was measured by electrochemiluminescence immunoassay on a Roche Modular E180 analyzer (Roche Diagnostics $\mathrm{GmbH}$, Mannheim, Germany) with an intraassay CV of $1.1 \%$ and an inter-assay $\mathrm{CV}$ of $1.8 \%$ at serum concentration $48.7 \mathrm{ng} / \mathrm{l}(\mathrm{n}$ 11). Serum Ca was analyzed by a Roche Modular P analyzer (Roche Diagnostics GmbH, Mannheim, Germany). The concentrations of $\mathrm{Ca}$ were within the reference range in all subjects.

\section{Statistical analysis}

All analyses were performed by using the Statistical Package for the Social Sciences for Windows (release 10.0; Norusis/ SPSS Inc., Chicago, USA). Values of normally distributed variables were expressed as means and standard deviations. Statistical comparisons between groups were made by the $t$ test or by ANOVA with Tukey's test. The normality of the variables was tested using the Shapiro-Wilk $W$ test. If the variables were non-normally distributed, descriptive values were expressed as medians and interquartile ranges. Statistical comparisons between groups were made using the Kruskal-Wallis test with Bonferroni's adjusted Mann-Whitney $U$ test. Spearman's rank correlations were used for correlation analyses. Since the distribution of the MET values was non-normal, the square roots of the MET values were used. The significance level was set at $P<0 \cdot 05$. The most important descriptive values were expressed with $95 \%$ CI.

\section{Results}

The characteristics of the subjects in 2000 and at the end of the study in 2004 are presented in Table 1. In 2000 none of the girls were pre-pubertal, eleven were pubertal, and 131 mature. At the end of the follow-up in 2004 all were classified as mature. One participant had given birth during follow-up. The median of leisure time physical activity decreased by $21.6 \%$, from $25.5 \mathrm{MET} \mathrm{h} /$ week in 2000 to $20.0 \mathrm{MET}$ $\mathrm{h} /$ week in 2004.

The mean daily dietary intake of vitamin $\mathrm{D}$ assessed by FFQ was $4.0 \mu \mathrm{g}$ in 2000 and $5.4 \mu \mathrm{g}$ in 2004; the corresponding values for $\mathrm{Ca}$ were $1522 \mathrm{mg}$ and $1116 \mathrm{mg}$ (Table 1). There were no differences in mean daily dietary intake of $\mathrm{Ca}$ or vitamin $\mathrm{D}$ by physical activity tertiles at the beginning or at the end of study (data not shown). The mean daily dietary vitamin D intake was $3.0(95 \%$ CI $1.9,4.2) \mu$ g greater $(P<0.0001)$ in the highest than in the lowest daily dietary $\mathrm{Ca}$ intake tertile. 
Table 1. Characteristics of study population ( $n$ 142) in years 2000 and 2004. Results are expressed as unadjusted mean values with standard deviation; the ratio of work metabolic rate hours (MET) per week values are medians with interquartile range (IQR; first, third quartile). Tanner stage are presented as frequencies $(1=$ prepubertal girls, $2=$ pubertal girls, $3=$ mature girls)

\begin{tabular}{|c|c|c|c|c|c|c|c|c|}
\hline \multirow[b]{2}{*}{ Characteristic } & \multicolumn{4}{|c|}{ Year 2000} & \multicolumn{4}{|c|}{ Year 2004} \\
\hline & Mean & SD & Median & IQR & Mean & SD & Median & IQR \\
\hline Age (years) & $16 \cdot 0$ & $1 \cdot 8$ & & & $20 \cdot 0$ & $1 \cdot 8$ & & \\
\hline Height $(\mathrm{cm})$ & $164 \cdot 6$ & 6.5 & & & $166 \cdot 2$ & $6 \cdot 3$ & & \\
\hline Weight (kg) & $55 \cdot 3$ & 8.3 & & & 59.9 & 8.7 & & \\
\hline BMI $\left(\mathrm{kg} / \mathrm{m}^{2}\right)$ & $20 \cdot 4$ & 2.5 & & & $21 \cdot 7$ & $2 \cdot 8$ & & \\
\hline Dietary vitamin $D$ intake $(\mu \mathrm{g} / \mathrm{d})$ & 4.0 & $2 \cdot 2$ & & & 5.4 & $2 \cdot 6$ & & \\
\hline Dietary Ca intake $(\mathrm{mg} / \mathrm{d})$ & 1522 & 577 & & & 1116 & 482 & & \\
\hline $\mathrm{S}-25(\mathrm{OH}) \mathrm{D}(\mathrm{nmol} / \mathrm{l})$ & 48.3 & 19.6 & & & $48 \cdot 1$ & $17 \cdot 1$ & & \\
\hline S-PTH (ng/l) & NA & & & & $32 \cdot 02$ & $13 \cdot 2$ & & \\
\hline Leisure time physical activity (MET h/week)* & & & $25 \cdot 5$ & $12 \cdot 0,75 \cdot 0$ & & & $20 \cdot 0$ & $8 \cdot 8,40 \cdot 0$ \\
\hline Tanner stage & & & & & & & & \\
\hline 1 & 0 & & & & 0 & & & \\
\hline 2 & 11 & & & & 0 & & & \\
\hline 3 & 131 & & & & 142 & & & \\
\hline
\end{tabular}

S-25(OH)D, serum 25-hydroxyvitamin D; S-PTH, serum parathyroid hormone; NA, not available.

* The ratio of work metabolic rate hours (MET) per week was calculated by multiplying frequency, mean duration and mean intensity of weekly physical activity.

The recommended daily dietary intake of $\mathrm{Ca}$ in Finland is $900 \mathrm{mg}$ for children and teenagers (10-17 years) and $800 \mathrm{mg}$ for 18 years and older. In 2000 the proportion of participants who did not reach $800 \mathrm{mg}$ was $9.2 \%$ and in 2004 it was $26.8 \%$. The recommended intake of vitamin $\mathrm{D}$ was increased to $7.5 \mu \mathrm{g}(300 \mathrm{IU}) / \mathrm{d}$ in the year 2005; previously it was $5 \mu \mathrm{g}(200 \mathrm{IU}) / \mathrm{d}$. The mean daily dietary intake of vitamin D was $<7.5 \mu \mathrm{g}$ in $91.5 \%$ of the participants in 2000 and $83.8 \%$ in 2004 . Only eight participants $(5.6 \%)$ took $\mathrm{Ca}$ supplementation and sixteen $(11.3 \%)$ took vitamin D supplementation at least three times per week at the end of the follow-up period. The fact that food had been fortified with vitamin $\mathrm{D}$ did increase the daily dietary intake of vitamin $\mathrm{D}$, and this increase correlated significantly with $\mathrm{S}-25(\mathrm{OH}) \mathrm{D}$ concentration $(r$ 0.295, $P<0.0001)$. The mean daily dietary $\mathrm{Ca}$ intake correlated significantly with $\mathrm{S}-25(\mathrm{OH}) \mathrm{D}$ at the end of study period $(r 0.224, P=0.008)$. The daily dietary intakes of $\mathrm{Ca}$ and vitamin $\mathrm{D}$ correlated significantly at the beginning of the study $(r 0.435, P<0.0001)$ and at the end of study period $(r 0.515, P<0.0001)$. The level of serum $\mathrm{Ca}$ did not correlate with the concentrations of S-25(OH)D or S-PTH.

S-25(OH)D did not differ significantly between the age tertiles or physical activity tertiles at the beginning or at the end of follow-up (data not shown). Neither S-25(OH)D between the highest and lowest $\mathrm{Ca}$ intake tertiles nor between the highest and lowest vitamin D intake tertiles differed significantly. The midwinter (February-March) mean concentrations of S-25(OH)D did not change significantly during follow-up period ( 48.3 v. $48.1 \mathrm{nmol} / \mathrm{l}$, NS), but the standard deviations of the $25(\mathrm{OH}) \mathrm{D}$ concentrations decreased during the followup (Table 1).

The impact of vitamin D fortification is shown in Table 2 and Fig. 1. The cumulative prevalence of severe hypovitaminosis $\mathrm{D}(\mathrm{S}-25(\mathrm{OH}) \mathrm{D}<20 \mathrm{nmol} / \mathrm{l})$ was $1.4 \%$ in 2000 and $0.7 \%$ in 2004 . The proportion of participants who had S-25 $(\mathrm{OH}) \mathrm{D}$ concentration $<50 \mathrm{nmol} / 1$ was $60.6 \%$ in 2000 and $65.5 \%$ in 2004 . The cumulative prevalence of $\mathrm{S}-25(\mathrm{OH}) \mathrm{D}$ concentrations $<75 \mathrm{nmol} / \mathrm{l}$ at 2000 and 2004 visits was similar (93\% v. $93 \%$ ) despite changed vitamin D fortification in 2003 .
Only $7.0 \%$ of the participants had an adequate S-25(OH)D $(\geq 75 \mathrm{nmol} / \mathrm{l})$ level in 2000 and in 2004. The S-PTH concentration was measured only in 2004 and the mean concentration was $32.0 \mathrm{ng} / \mathrm{l}$. There was a trend towards a low concentration of PTH when the concentration of $\mathrm{S}-25(\mathrm{OH}) \mathrm{D}$ was high $(r-0.143, \quad P=0.092)$. S-PTH did not differ significantly between the tertiles of daily dietary $\mathrm{Ca}$ intake at the end of the follow-up.

\section{Discussion}

The main finding of this study is that the average dietary intake of vitamin D in Finland remains insufficient among adolescent females despite vitamin $\mathrm{D}$ fortification of liquid milk products, margarines and spreads. Despite fortification the midwinter mean concentrations of S-25(OH)D were unsatisfactory when the values in 2000 were compared to the values in 2004. However, some effect from the fortification programme was revealed by the decline in the incidence of severe hypovitaminosis D from two to one participant. Only $7.0 \%$ of the participants had S-25(OH)D levels $\geq 75 \mathrm{nmol} / 1$ during midwinter. In the present study $73 \%$ of the participants consumed at least $800 \mathrm{mg} \mathrm{Ca} / \mathrm{d}$, while only $16 \%$ consumed

Table 2. Cumulative prevalence (\%) of vitamin $D(S-25(O H) D)$ insufficiency in study population ( $n$ 142) in 2000 and 2004. Serum parathyroid hormone (S-PTH) results are expressed as means with their standard deviation

\begin{tabular}{|c|c|c|c|c|c|c|}
\hline \multirow[b]{3}{*}{ S-25(OH)D (nmol/l) } & \multirow{2}{*}{\multicolumn{2}{|c|}{ Year 2000}} & \multirow{2}{*}{\multicolumn{2}{|c|}{ Year 2004}} & \multirow{2}{*}{\multicolumn{2}{|c|}{$\frac{\text { Year } 2004}{\text { S-PTH }(n g / l)}$}} \\
\hline & & & & & & \\
\hline & $n$ & $\%$ & $n$ & $\%$ & Mean & SD \\
\hline$<20$ & 2 & 1.4 & 1 & 0.7 & $60 \cdot 1$ & \\
\hline$<37.5$ & 37 & $26 \cdot 1$ & 34 & 23.9 & 34.5 & $16 \cdot 9$ \\
\hline$<50$ & 86 & $60 \cdot 6$ & 93 & 65.5 & $33 \cdot 1$ & $13 \cdot 6$ \\
\hline$<75$ & 132 & $93 \cdot 0$ & 132 & 93.0 & $32 \cdot 4$ & $13 \cdot 3$ \\
\hline$\geq 75$ & 142 & 100 & 142 & 100 & $26 \cdot 5$ & 11.4 \\
\hline
\end{tabular}



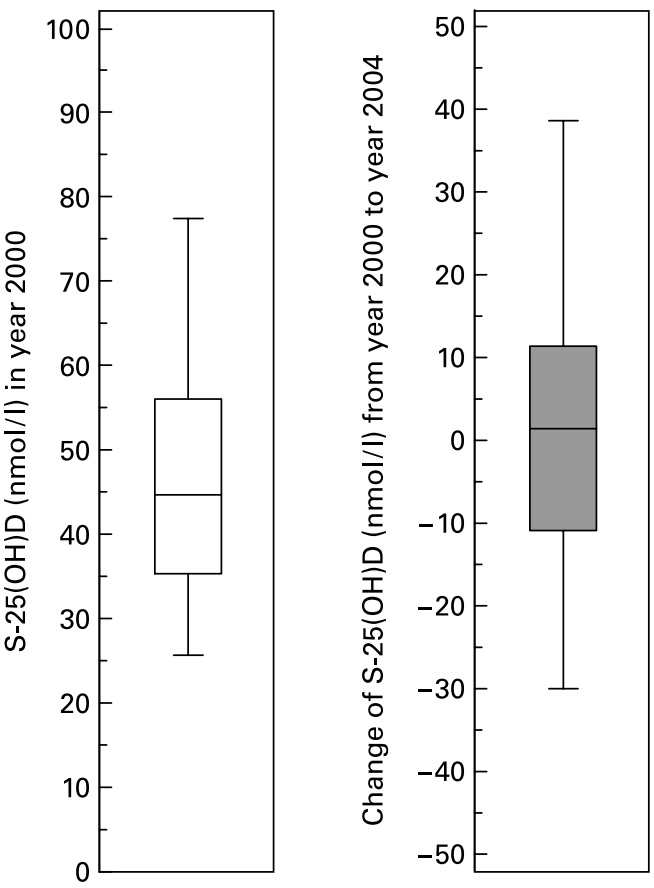

Fig. 1. Serum 25-hydroxyvitamin $D(\mathrm{~S}-25(\mathrm{OH}) \mathrm{D})$ concentrations $(\mathrm{nmol} / \mathrm{l})$ in study population ( $n$ 142) in 2000 and change of S-25(OH)D concentration $(\mathrm{nmol} / \mathrm{l})$ from 2000 to 2004 . The box shows the distance between the quartiles, with the median marked as a horizontal line, and the vertical bars indicating the 5th and 95th percentiles.

$7 \cdot 5 \mu \mathrm{g}$ vitamin $\mathrm{D} / \mathrm{d}$. Nutrition guidelines targeted at children and adolescents to optimize bone health have focused on $\mathrm{Ca}$ and exercise, but have often neglected vitamin $\mathrm{D}^{(21,22)}$. This study shows that there is still much work to be done to guarantee a sufficient supply of vitamin D for adolescent females.

The current adult recommendations for vitamin D (7.5-10 $\mu \mathrm{g} / \mathrm{d}(300-400 \mathrm{IU}))$ are inadequate in comparison to the natural generation of vitamin D: whole-body exposure to peak summer sun without sunscreen at latitude $40^{\circ} \mathrm{N}$ for only $15 \mathrm{~min}$ will generate and release $>250 \mu \mathrm{g}(10000 \mathrm{IU})$ vitamin $\mathrm{D}_{3}$ into the circulation ${ }^{(23)}$. The total daily requirement of vitamin D is approximately $100 \mu \mathrm{g}$ (4000 IU) based on metabolic utilization of vitamin $D_{3}$, not $5-10 \mu \mathrm{g}$ (200-400 IU). In young individuals, most of this originates from the skin ${ }^{(24)}$, but cutaneous vitamin $\mathrm{D}_{3}$ synthesis depends strongly on latitude and season ${ }^{(25)}$. Finland is located at latitude $61-71^{\circ} \mathrm{N}$, and sunshine exposure is unable to produce vitamin $\mathrm{D}$ in the skin of adolescent females for at least half the year at this latitude. Recent studies show that the current dietary recommendations for adults are not sufficient to maintain S-25(OH)D concentrations $\geq 75 \mathrm{nmol} / \mathrm{l}^{(7,23,26)}$. According to recent data, the tolerable upper intake level set at $50 \mu \mathrm{g} / \mathrm{d}$ (2000 IU) in Europe and North America is too low to permit optimization of vitamin D concentrations in the serum in the general population and for public health ${ }^{(7,26)}$.

In a Swiss study there was a higher incidence of vitamin $D$ insufficiency $(25(\mathrm{OH}) \mathrm{D}<30 \mathrm{nmol} / \mathrm{l})$ in older adolescent boys and girls than in younger ones, which may reflect a more sedentary lifestyle or an increased utilization of vitamin $\mathrm{D}^{(27)}$. Our study does not confirm these findings, since tertiles of age or physical activity did not affect the
$25(\mathrm{OH}) \mathrm{D}$ levels. In a recent study conducted in wintertime in Denmark, Finland, Ireland and Poland, $37 \%$ of the adolescent girls had a vitamin $\mathrm{D}$ concentration of $<25 \mathrm{nmol} / \mathrm{l}$ and $92 \%$ of $<50 \mathrm{nmol} / 1$ and the corresponding figures of the Finnish subgroup were $37 \%$ and $97 \%{ }^{(3)}$. In the present study $65.5 \%$ of our participants had vitamin D concentrations in serum $<50 \mathrm{nmol} / \mathrm{l}$ despite the added fortification of foodstuffs.

The incremental consumption of $1 \mu \mathrm{g}$ vitamin $\mathrm{D}_{3}$ daily raises $\mathrm{S}-25(\mathrm{OH}) \mathrm{D}$ by approximately $1 \mathrm{nmol} / \mathrm{l}^{(26)}$. In Germany, supplementation with vitamin D did augment vitamin D intake but failed to achieve $80 \%$ of the recommended levels in almost all age groups (2-18 years) and the highest use of various vitamin-containing supplementation was encountered in subjects aged 15-18 years ${ }^{(28)}$. Young Canadian females had an intake of vitamin D from milk and/or multivitamins that did not relate to the prevention of low vitamin D status in winter, since the recommended vitamin $\mathrm{D}$ intakes were far too small to prevent insufficiency ${ }^{(6)}$. In our study, $11 \%$ of the adolescent participants consumed vitamin D supplementation and only $6 \% \mathrm{Ca}$ supplementation, and the amount of self-reported vitamin D supplementation although rare, was also low, only $5-10 \mu \mathrm{g}$ daily in the dark season of the year. A recent study on young people living in Northern Ireland also demonstrated inadequate consumption of dietary vitamin $\mathrm{D}$ and low vitamin D status. However, supplementation with $15 \mu \mathrm{g}$ vitamin $\mathrm{D}_{3}$ daily during two winter months raised the average $\mathrm{S}-25(\mathrm{OH}) \mathrm{D}$ concentration from $48 \mathrm{nmol} / \mathrm{l}$ to $86 \mathrm{nmol} / \mathrm{l}^{(29)}$. The wintertime vitamin D status of our study group was on the same level as the baseline winter vitamin D status of the Irish group.

Supplementation may not be realistic in this age group and adequate food fortification with vitamin $\mathrm{D}$ would be more effective. Laaksi and colleagues found that fortification of liquid milk products and margarines reduced significantly the occurrence of vitamin D insufficiency among young Finnish military conscripts, although one-third still remained vitamin $\mathrm{D}$ deficient ${ }^{(30)}$. The discrepancy between the increase of $25(\mathrm{OH}) \mathrm{D}$ concentrations after fortification in the present study and the results in the military conscript study might depend on a very high consumption of liquid milk products and margarines among the physically active conscripts. However, the winter concentrations of $25(\mathrm{OH}) \mathrm{D}$ were at the same level after fortification as in our study. If the dietary $\mathrm{Ca}$ intake of adolescent participants in our study, probably due to low milk consumption, had not diminished during the follow-up period, the benefit of vitamin D fortification to vitamin D status would have been evident. Our results agree with those of Lamberg-Allardt and co-workers who found that teenage girls and young women particularly were prone to a poor vitamin D status despite increased vitamin D intake ${ }^{(16)}$. Consumption of fortified milk products, spreads and fish seems to be clearly insufficient as a means to improve the vitamin D balance of teenage girls and young women. There are a number of adolescent girls and women who are not reached by the current fortification policy, as shown also by our study. Natri and colleagues found that vitamin D-fortified bread could be a feasible way of improving vitamin D nutrition ${ }^{(15)}$. Orange juice also has been proved to be potential vehicle for vitamin $D$ fortification ${ }^{(31)}$. Since excessive amounts of vitamin D are toxic, it is better to add fortified foodstuffs cautiously, e.g. 
to one or a few brands of bread, and follow up the benefits and possible risks of the fortification.

Vitamin D has been recognized for almost 100 years as being essential for bone health. Vitamin D is needed for adequate $\mathrm{Ca}$ and $\mathrm{P}$ absorption, which is a requirement for normal development and mineralization of the healthy skeleton. We have shown earlier that teenage girls who had a S-25(OH)D concentration $<50 \mathrm{nmol} / 1$ were at risk of losing their bone mineral density of the lumbar spine during a 3-year followup period ${ }^{(10)}$. Viljakainen and colleagues have shown that daily $\mathrm{D}_{3}$ supplementation for 1 year improved bone mineral augmentation in 11-12-year-old girls ${ }^{(4)}$. Javaid and coworkers demonstrated that maternal vitamin $\mathrm{D}$ inadequacy during pregnancy affected negatively the skeletal bone mineral accrual of the offspring over the next 9 years $^{(32)}$. In our study group only one participant had given birth and the remaining cohort is rapidly reaching childbearing age. Arkkola and colleagues reported that taking food and supplementation into account, $85 \%$ of Finnish pregnant women had total vitamin $\mathrm{D}$ intake below recommendation ${ }^{(33)}$. Women of childbearing age and the healthcare professionals responsible for the care of pregnant women should be aware of the risk of the vitamin D inadequacy. In a recent study a lower than average concentration of $25(\mathrm{OH}) \mathrm{D}$ was a predisposing factor for bone stress fractures in healthy young Finnish male military recruits ${ }^{(34)}$. There is no reason to believe that current fortification of foodstuffs in Finland has resolved the vitamin D problem.

The strength of our study is follow-up of the same cohort of the growing participants. The drop-out rate was modest, only $17 \%$ during 4 years of follow-up. Although selection bias cannot be ruled out as an explanation for initial differences at baseline in concentrations of $25(\mathrm{OH}) \mathrm{D}$, it could not confound the change of $25(\mathrm{OH}) \mathrm{D}$ concentrations.

The most important limitation of our study is that we have made only observations about increased vitamin $\mathrm{D}$ intake and its consequence on the vitamin D status in this cohort. Secondly, in comparison to our former studies ${ }^{(2,10)}$, we have observed currently an average increase of about $20 \%$ in measured levels of $25(\mathrm{OH}) \mathrm{D}$ concentrations, although we have used the same $25(\mathrm{OH}) \mathrm{D}$ assay kit from same manufacturer with same samples. This is due to change of antiserum in the $25(\mathrm{OH}) \mathrm{D}$-kit during these years. For this reason the samples of the year 2000 were reanalyzed to exclude this analytical difference between the samples. The samples were stored at $-70^{\circ}$ without extra thawing until analysis. According to previous observations the $\mathrm{S}-25(\mathrm{OH}) \mathrm{D}$ concentration appears to be stable during storage ${ }^{(35,36)}$.

It is important to stress that the estimation of dietary intakes of $\mathrm{Ca}$ and vitamin $\mathrm{D}$ are very challenging. Ca intake assessments by FFQ are mainly based on the consumption of milk products during four weeks, while the FFQ of vitamin D take into account periods of three months. All participants had filled in FFQ several times during the study but there still remained possibilities for over- or underestimation. S-25(OH)D has been earlier shown to correlate weakly but significantly with vitamin D intake as assessed by FFQ, but not by a 4-d food recording among our study participants ${ }^{(2)}$.

Our study confirms that vitamin D is a risk nutrient among adolescent females despite current fortification of foodstuffs in Finland. Vitamin D intake is insufficient to maintain the vitamin D status at an adequate level in the dark season of the year when the skin is not able to produce enough vitamin D. Because vitamin D inadequacy may affect bone metabolism and other organ systems adversely, more attention should be paid to adequate $\mathrm{S}-25(\mathrm{OH}) \mathrm{D}$ levels particularly in teenage girls and adolescent women. A reduced store of vitamin $D$ is not improved by mild fortification of items such as milk products, margarines and spreads. Despite having been increased recently, current fortification of food with vitamin D in Finland is still not enough to have a meaningful effect on $25(\mathrm{OH}) \mathrm{D}$ concentrations in adolescent females. Health education should emphasize the benefit of vitamin $\mathrm{D}$ for the general health of people, rather than inducing fears of vitamin D toxicity. This message will help many adolescent and young women to consume vitamin Dcontaining milk products. In the future fortification of a wide selection of foodstuffs, not only milk products, should be considered. Meanwhile, at northern latitudes, such as Finland, regular supplementation with vitamin $\mathrm{D}$ should be encouraged for adolescents.

\section{Acknowledgements}

The study was supported by The Turku University Foundation and the Medical Research Foundation of the Turku University Central Hospital. There are no conflicts of interest.

All investigators contributed to the study design and writing of the paper. M. L.-V. recruited the patients, contributed to data analysis and wrote the first draft of the manuscript. T. M. was the leader of the study, advised and took an active role in the study design, conducted data analysis, performed statistical analyses and revised the manuscript. A. L. supervised the laboratory work and revised the manuscript. O. J. H. contributed to attainment of questionnaires and revision of the manuscript. E. R. conducted the interviews and revision of the manuscript. J. V. contributed to the data management and revision of the manuscript and supervised the study.

\section{References}

1. Docio S, Riancho JA, Perez A, Olmos JM, Amado JA \& Gonzalez Macias J (1998) Seasonal deficiency of vitamin D in children: a potential target for osteoporosis-preventing strategies? J Bone Miner Res 13, 544-548.

2. Lehtonen-Veromaa M, Möttönen T, Irjala K, Kärkkäinen M, Lamberg-Allardt C, Hakola P \& Viikari J (1999) Vitamin D intake is low and hypovitaminosis D common in healthy 9- to 15-year-old Finnish girls. Eur J Clin Nutr 53, 746-751.

3. Andersen R, Molgaard C, Skovgaard LT, et al. (2005) Teenage girls and elderly women living in northern Europe have low winter vitamin D status. Eur J Clin Nutr 59, 533-541.

4. Viljakainen HT, Natri A-M, Kärkkäinen M, Huttunen MM, Palssa A, Jakobsen J, Cashman KD, Molgaard C \& LambergAllardt C (2006) A positive dose-response effect of vitamin $\mathrm{D}$ supplementation on site-specific bone mineral augmentation in adolescent girls: A double-blinded randomized placebo-controlled 1-year intervention. J Bone Miner Res 21, 836-844.

5. Hollis BW (1996) Assessment of vitamin D nutritional and hormonal status: what to measure and how to do it. Calcif Tissue Int 58, 4-5.

6. Vieth R, Cole DE, Hawker GA, Trang HM \& Rubin LA (2001) Wintertime vitamin $\mathrm{D}$ insufficiency is common in young 
Canadian women, and their vitamin D intake does not prevent it. Eur J Clin Nutr 55, 1091-1097.

7. Heaney RP (2005) The vitamin D requirement in health and disease. J Steroid Biochem Mol Biol 97, 13-19.

8. Guillemant J, Taupin P, Le HT, Taright N, Allemandou A \& Peres G (1999) Vitamin D status during puberty in French healthy male adolescents. Osteoporosis Int 10, 222-225.

9. Outila TA, Kärkkäinen MU \& Lamberg-Allardt CJ (2001) Vitamin D status affects serum parathyroid hormone concentrations during winter in female adolescents: associations with forearm bone mineral density. Am J Clin Nutr 74, 206-210.

10. Lehtonen-Veromaa M, Möttönen T, Nuotio I, Irjala K, Leino A \& Viikari J (2002) Vitamin D and attainment of peak bone mass among peripubertal Finnish girls: a 3-year prospective study. Am J Clin Nutr 76, 1446-1453.

11. El-Hajj Fuleihan G, Nabulsi M, Tamim H, Maalouf J, Salamoun M, Khalife H, Choucair M, Arabi A \& Vieth R (2006) Effect of vitamin $\mathrm{D}$ replacement on musculoskeletal parameters in school children: a randomized controlled trial. J Clin Endocrinol Metab 91, 405-412.

12. Holick MF (2005) The vitamin D epidemic and its health consequences. J Nutr 135, 2739S-2748S.

13. Garland CF, Garland FC, Gorham ED, Lipkin M, Newmark H, Mohr SB \& Holick MF (2006) The role of vitamin D in cancer prevention. Am J Public Health 96, 252-261.

14. Tylavsky FA, Cheng S, Lyytikäinen A, Viljakainen H \& Lamberg-Allardt C (2006) Strategies to improve vitamin D status in northern European children: exploring the merits of vitamin D fortification and supplementation. J Nutr 136, 1130-1134.

15. Natri A-M, Salo P, Vikstedt T, Palssa A, Huttunen M, Kärkkäinen MUM, Salovaara H, Piironen V, Jakobsen J \& Lamberg-Allardt C (2006) Bread fortified with cholecalciferol increases the serum 25-hydroxyvitamin D concentration in women as effectively as a cholecalciferol supplement. $J$ Nutr 136, 123-127.

16. Lamberg-Allardt C, Viljakainen H \& Working Group (2006) Follow-up study on the vitamin D status in the Finnish population 2002 and 2004. In Reports of the Ministry of Social Affairs and Health, pp. 1-49 Helsinki, Finland: Ministry of Social Affairs and Health.

17. Tanner JM (1962) Growth at Adolescence, pp. 1-212. Oxford: Blackwell Scientific Publications.

18. Uusi-Rasi K, Salmi HM \& Fogelholm M (1994) Estimation of calcium and riboflavin intake by a short diary. Scand $J$ Nutr 38, $122-124$.

19. Rautava E, Lehtonen-Veromaa M, Möttönen T, Kautiainen H, Heinonen OJ \& Viikari J (2006) Association of reduced physical activity and quantitative ultrasound measurements: A 6-year follow-up study of adolescent girls. Calcif Tissue Int 79, 50-56.

20. Sullivan SS, Rosen CJ, Halteman WA, Chen TC \& Holick MF (2005) Adolescent girls in Maine are at risk for vitamin D insufficiency. J Am Diet Assoc 105, 971-974.

21. Matkovic V (1991) Calcium metabolism and calcium requirements during skeletal modeling and consolidation of bone mass. Am J Clin Nutr 54, Suppl. 1, S245-S260.

22. Weaver CM, Peacock M \& Johnston CC Jr (1999) Adolescent nutrition in the prevention of postmenopausal osteoporosis. $J$ Clin Endocrinol Metab 84, 1839-1843.
23. Hollis BW (2005) Circulating 25-hydroxyvitamin D levels indicative of vitamin D sufficiency: implications for establishing a new effective dietary intake recommendation for vitamin D. J Nutr 135, 317-322.

24. Heaney RP, Davies KM, Chen TC, Holick MF \& Barger-Lux MJ (2003) Human serum 25-hydroxycholecalciferol response to extended oral dosing with cholecalciferol. Am J Clin Nutr 77, 204-210.

25. Webb AR, Kline L \& Holick MF (1988) Influence of season and latitude on the cutaneous synthesis of vitamin D3: exposure to winter sunlight in Boston and Edmonton will not promote vitamin D3 synthesis in human skin. J Clin Endocrinol Metab 67, 373-378.

26. Vieth R (2006) Critique of the considerations for establishing the tolerable upper intake level for vitamin D: critical need for revision upwards. J Nutr 136, 1117-1122.

27. Ginty F, Cavadini C, Michaud PA, Burckhardt P, Baumgartner M, Mishra GD \& Barclay DV (2004) Effects of usual nutrient intake and vitamin D status on markers of bone turnover in Swiss adolescents. Eur J Clin Nutr 58, 1257-1265.

28. Sichert-Hellert W, Wenz G \& Kersting M (2006) Vitamin intakes from supplements and fortified food in German children and adolescents: results from the DONALD Study. J Nutr 136, 1329-1333.

29. Barnes MS, Robson PJ, Bonham MP, Strain JJ \& Wallace JM (2006) Effect of vitamin D supplementation on vitamin D status and bone turnover markers in young adults. Eur J Clin Nutr 60, 727-733.

30. Laaksi IT, Ruohola J-PS, Ylikomi TJ, Auvinen A, Haataja RI, Pihlajamäki HK \& Tuohimaa PJ (2006) Vitamin D fortification as public health policy: significant improvement in vitamin D status in young Finnish men. Eur J Clin Nutr 60, 1035-1038.

31. Tangpricha V, Koutkia P, Rieke SM, Chen TC, Perez AA \& Holick MF (2003) Fortification of orange juice with vitamin D: a novel approach for enhancing vitamin D nutritional health. Am J Clin Nutr 77, 1478-1483.

32. Javaid MK, Crozier SR, Harvey NC, Gale CR, Dennison EM, Boucher BJ, Arden NK, Godfrey KM, Cooper C \& the Princess Anne Hospital Study Group (2006) Maternal vitamin D status during pregnancy and childhood bone mass at age 9 years: a longitudinal study. Lancet 367, 36-43.

33. Arkkola T, Uusitalo U, Pietikäinen M, Metsälä J, Kronberg-Kippilä C, Erkkola M, Veijola R, Knip M, Virtanen S \& Ovaskainen M-L (2006) Dietary intake and use of dietary supplements in relation to demografic variables among pregnant Finnish women. $\mathrm{Br} J$ Nutr 96, 913-920.

34. Ruohola J-P, Laaksi I, Ylikomi T, Haataja R, Mattila VM, Sahi T, Tuohimaa P \& Pihlajamäki H (2006) Association between serum 25(OH)D concentrations and bone stress fractures in Finnish young men. $J$ Bone Miner Res 21, 1483-1488.

35. Antoniucci DM, Black DM \& Sellmeyer DE (2005) Serum 25hydroxy-vitamin $\mathrm{D}$ is unaffected by multiple freeze-thaw cycles. Clin Chem 51, 258-261.

36. Piirainen T, Laitinen K \& Isolauri E (2007) Impact of national fortification of fluid milks and margarines with vitamin $\mathrm{D}$ on dietary intake and serum 25-hydroxyvitamin D concentration in 4-year-old children. Eur J Clin Nutr 61, 123-128. 